\title{
Scaling low resolution regional climate model results to high resolution for Predicting Rice and Maize Production under Climate Change Disaster Scenario
}

\author{
Teerachai Amnuaylojaroen ${ }^{1,3}$, Pavinee Chanvichit ${ }^{2}$ \\ ${ }^{1}$ School of Energy and Environment, University of Phayao, Phayao, Thailand, 56000 \\ ${ }^{2}$ School of Agriculture and Natural Resources, University of Phayao, Phayao, Thailand, 56000 \\ ${ }^{3}$ Atmospheric Pollution and Climate Change Research Units, School of Energy and \\ Environment, University of Phayao, Phayao, Thailand, 56000
}

Corresponding author: email: teerachai4@gmail.com, tel:+6654-466-666, fax:+6654-466-690

ORCID no: 0000-0003-2758-2592

\section{Highlight:}

- Downscaling regional climate model output using statistical method

- Coupling regional climate model and the Decision Support System for the Transfer of Agrotechnology

- The coupled model indicate rice and maize production will decrease in the future.

\begin{abstract}
Climate change effect on human-living in verities of way such as health and food security. This study presents predicting crop yields, and production risk in the near future (2020-2029) in northern Thailand using coupling $1 \mathrm{~km}$ resolution of regional climate model which is downscaled using a conservative remapping method and the Decision Support System for the Transfer of Agrotechnology (DSSAT) modeling system. The accuracy of the climate and agricultural model was appropriate compared to the observations with Index of Agreement (IOA) in ranges of $0.65-0.89$. The DSSAT modeling system predicts that rice, and maize production will decrease by $5 \%$ and $4 \%$ in northern Thailand. In addition, a short-term risk analysis of rice and maize production has shown that, in the context of climate change, maize production appears to be at a high risk of low production in the near future, while rice cultivation might be a low risk.
\end{abstract}

Keywords: Future rice production, Future maize production, Hybrid dynamical statistical, Climate change, Agriculture, Thailand

\section{Introductions}

Climate change involves changes beyond the atmospheric average caused both by natural factors such as the Earth's orbit, volcanic activities and by artificial factors such as the increase in greenhouse gas concentration and aerosol. Global climate change, which refers to the average global temperature increases, has become a megatrend leading to major global changes in the future. According to the United Nations IPCC 's fourth report in 2007, on Climate Change, global warming is undoubtedly having a severe impact on the world and the increase in greenhouse gas emissions from anthropogenic activity has caused global warming since the mid-20th century. It takes at least five to ten years to assess the impacts and vulnerability of climate change and to prepare adequate countermeasures. In particular, since agriculture is climate dependent and therefore, susceptible to climate change, it is very urgent to prepare climate change adaptation measures. Adequate countermeasures based on scientific diagnoses and climate change impact assessments on agriculture in Asian countries are essential to the development of future agricultural vision and administration policies. This will 
also provide valuable information for local governments to develop mid- to long-term agricultural development plans and to prepare their production plans for farming households.

Agricultural production is done through the selection and implementation of appropriate methods of agriculture by selecting cultures suitable to the climate of a certain region. There are, therefore, notable regional characteristics of agriculture as a climate-based bio-industry. Regional features are based on climate-determined features of the ecosystem of the region. Climate change disrupts the agricultural ecosystem and causes a change in the temperatures, precipitation, and sunlight of agricultural climate, while also further influencing the arable, livestock, and hydrological sectors. Evaluation of the consequences of the recent climate change complements long-term forecasts and identifies which crops and sites are more vulnerable. Agricultural productivity in several South-east Asian regions has decreased, due to the large measure of heat, and water stresses and climate variability that had a threat to food security in the region. The main influences of agricultural production in South-East Asia are temperature and precipitation. In many areas of the region, the potential for the production of important crops like rice and maize has fallen as hot weather and watered stress rates have increased. A study by Peng et al., 2004 found that in the period from year 1991 to 2003 rice output decreased by $10 \%$ for every level of increase in the minimum temperature. In Thailand, the increasing temperature, in particular in non-irrigated rice, has been reported to lead to a decrease in crop yield. This is because dryness in critical growth stages such as the flowering period is having a negative effect. Rice in all provinces (more than 58 provinces) is cultivated in Thailand. In the northeast more than $50 \%$ of all rice zones. The main rice season lasts between May and December in north and north-eastern regions, while the main rice crops in southern regions last from September to May. Upland rice in mountainous areas of the northern hilly areas, the far northwest and in certain parts of the south, has a relatively small retention area. Climate change, especially in Thailand, is potentially affecting agriculture. Agriculture values are substantially determined by both temperature and precipitation. Summer temperature, early rain, and summer precipitation negatively affect agricultural land values, while late rainy and winter precipitations improve agricultural land values (Attavanich, 2013). Rice and maize have been affected by climate change in two, main agricultural productivity in northern Thailand. Rice and Maize products fell by $12 \%$ in 2019 and $6 \%$ in comparison to 2018. The main-season crop production is estimated officially at 24.3 million tons, $3 \%$ below the average of five years. Although the planted area has been above average, dry spells and floods have caused crop losses, leading to a decrease in both the area and output harvested. The secondary season is projected at 4.1 million tons, more than 30 percent below the five-year average due to the critically low level of irrigation water supply which, together with loweraverage rainfall from January to March, will prevent and abort seeding operations where most seeding operations normally take place (http://www.fao.org/giews/countrybrief/country.jsp?code=THA).

To understand and provide context for national or regional impact studies on food safety, agriculture and climate change, a coupled regional climate model and crop model are crucial to understanding the cumulative effects of climate change to the agricultural sectors across the region. It is difficult and expensive to model locally across such a diverse region. The methods used in local and regional studies are often identical or similar, and therefore there are economies of scale in the management of crops, species, and ecosystems in regional areas. The fine resolution of environmental factors such as temperature, precipitation, and solar radiation is necessary to combine the regional climate model with the crop model. Approximately $1 \mathrm{~km}$ of grid distance is to be used to increase regional climate model resolution. Scaling a coarse resolution of regional climate data to a finer resolution, dynamic statistical downscaling is a way to increase climate data. The dynamic-statistical downscaling method combines a strategy of both regional and statistical downscaling merits. 
Dynamic downscaling enables the physics underlying the local climate reaction to be examined and leads to greater credibility. Furthermore, dynamic downscaling can record significant climate changes that could otherwise not have happened due to physical realism and the ability to simulate complex local processes (e.g. Caldwell et al., 2009; Salathé et al., 2008, 2010, Arritt and Rummukainen 2011, Pierce et al., 2013). Regional downscaling efforts were generally strongly criticized (e.g., Schiermeier 2010; Kerr 2011, 2013). One of the main critiques is that the GCM input limits low output. Each GCM itself may offer an incorrect picture of the true state of knowledge of climate change, including in the region of interest. This single GCM will also be misleading to be downgraded. This perception of accuracy at the regional level is particularly problematic if the dramatic under-sample of uncertainty reduces very little GCM. In this situation, the decreased output cannot reflect the most probable climate outcomes in the region and does not provide information on how regional uncertainty is manifested in the GCM ensemble. Prior studies usually have only two general downscaled models (e.g. Hayhoe et al. 2004; Duffy et al. 2006; Cayan et al. 2008; Salathé et al. 2010). This group is too small to obtain meaningful warming and uncertainty statistics. Instead, details from a wider band is preferred (Giorgi and Mearns 2002; Kharin and Zwiers, 2002). CMIP3 and CMIP5 sets are generally considered large enough to calculate meaningful sets and to cover the uncertainty area of climate change (Meehl et al., 2007, Taylor et al., 2012), including ten sets of members. Although the most likely results are to be determined and the uncertainty in the downscaling of a large ensemble characterized, this is not possible due to their high computational costs. Dynamic downscaling is in particular a costly technique and only a few global models have been used in most of the studies performing it. For example, Duffy et al.'s (2006) downscaling of PCM and HadCM 2, downscaling GFDL CM2.1, and CCSM3 by Pierce et al., (2013). The Coordinated Regional Downscaling Experiment (CORDEX; Giorgi et al. 2009) is also an example of dynamic downscaling but these are extremely large companies requiring coordination between several research groups. Large geographical areas also cover fewer resolutions (approximately $50 \mathrm{~km}$ ) than is necessary for this area of interest. Intense topographical areas and complex coastlines usually require a $10-15 \mathrm{~km}$ model resolution.

While, Statistical downscaling is a method by which high resolution climate or climate change information from relatively raw global climate models (GCMs) can be obtained. First statistical downscaling results in statistic relationships between observed small-scale and larger-scale (GCM) variables, either using analogous methods, regression analyzes or neural network methods. Future values of the major variables derived from the GCM future climate projections are then used to drive the statistical connections and thus to estimate the smaller details of the future climate. The example was found in Los Angeles, there are small mountain complexes, including Santa Monica Mountain, which play an important role in the development of local climatic gradients. These mountain complexes are only a few kilometers long and require even greater resolution and higher computer costs. The dynamical decline is thus an irremediable answer to the need for multimodel downscaling alone for this study. As the downscaling statistics are much cheaper for multimodel downscaling (i.e., Giorgi et al. 2001, Tebaldi et al. 2005, Pierce et al. 2013), it is almost always employed. The statistics on downscaling rely on empirical math from broad predictors to final predictors. These relationships are often much quicker than dynamic downscaling, making them ideal for reducing the number of major GCMs over time or scenarios. However, it is stationary to assume that the relationship between predictors and predictors continues even in a changing climate (Wilby and Wigley 1997). No complete supplement of variables such as dynamic downscaling is produced for each statistical model, even though these are essential instruments for downscaling multimodel assemblies.

The aim of this paper is to predict future rice and maize under the worst-case scenario of climate change RCP8.5 using a crop model which is embedded in The Decision Support 
System for Agrotechnology Transfer (DSSAT). Environmental inputs such as precipitation, temperature and solar radiation have been estimated on the basis of a scaling low-resolution regional climate model output $(10 \mathrm{~km})$ to a higher resolution $(1 \mathrm{~km})$. Regional climate data were based on the Nested Regional Climate Model with $10 \mathrm{~km}$ grid spacing (Amnuaylojaroen and Chanvijit, 2019). The statistical downscaling output was compared to observations such as ground-based measurement from the Thai Meteorological Department and Highly Resolved Observational Data Integration Towards Water Resource Evaluation (APHRODITE). While the output from DSSAT was compared to the farm data set from the Department of Agriculture in Thailand.

\section{Data used and Methodology}

\subsection{Data used}

We used the output from the Nested Regional Climate Model ( NRCM) for the current (1990-1999) and near-future climate (2020-2029) models under the Representative Concentration Pathway (RCP) 8.5 for the current (1990-1999) and the near-future climate (2020-2029). The model uses version 4 of the Community Climate System Model (CCSM) as initial and boundary conditions (Gen et al., 2011). The NRCM is a regional climate model based on Weather and Forecasting Model (WRF) (Skamarock et al., 2008) which uses the Community Climate System Model (CCSM) as the climate data forcing. It similarly uses a limited area to establish the initial and boundary conditions as a part of the Weather Research and Forecasting Model. While the PWP model is an oceanic mixing layer model that consolidates the mixing layer's convection adaptation and shear-instability. In the model configuration, a number of meteorological factors, i.e. wind, temperature, water vapor, and cloud hydrometeors were integrated into the Runge-Kutta integration method (skamarock et al., 2008). In the model, the feedback and evolutions of short- and long-wave atmospheric aerosol on radiation were calculated using Radiant Transfer Models (RRTMG) (Iacono et al., 2008). At the same time, the model includes aerosol feedback about meteorological processes such as cloud and precipitation effects calculated by Thompson (Thompson et al., 2004). In the simulation, the Grell-3 system was responsible for convection of the subgrid-scale. Both land and air were calculated through the Noah Land Surface Model (Chen and Dudhia 2001). Grid nudging for all vertical levels was applied in the outer domain in accordance with large-scale weather ( Stauffer and Seaman, 1990), with nudging coefficients of 00003 s-1 every 6 hours, for all variables including horizontal wind, temperature, and water vapor.

APHRODITE is a project involving several datasets, i.e. a Global Telecommunication System (GTS). The pre-compiled information set is a project included in the APHRODITE project. APHRODITE is also a highly resolved observational data integration to the assessment of water resources. Two datasets are based on GTS, including a Global Summary of the Day (GSOD) and the GHCN network. In addition, the pre-compiled dataset contains data from the GEWEX (Global Energy and Water Cycle Experiment) Asian Monsoon Experiment (GAME). The data for the project APHRODITE has been collected in Japan, China, Mongolia, Russia, Taiwan, and Nepal from national meteorological and hydrological services or individuals. The Dataset includes a resolution of $0.5 \times 0.5^{\circ}$ throughout Asia from 1973 to 2007 (Yasutomi et al., 2011).

\subsection{Methodology}

The production of rice and maize has been estimated in Northern Thailand based on the Crop Environmental Resource Synthesis-Rice (CERES-Rice) ( Ritchie et al., 1986) and the Crop Environmental Resource Synthesis-MAIZE (CERES-Maize) (Adnan et al., 2017) that are embedded in Decision for Supporting System for Agriculture Transfer (DSSAT) (Jone, 2003). The regional climate data from Domain 2 of the Nested Regional Climate Model (NRCM) 
simulation of Thailand, as described in Amnuaylojaroen and Chanvijit, 2019. The output from NRCM is from the climate-change scenario of the RCP8.5 Climate Change Approach, Thailand $\left[5^{\circ} \mathrm{N}-20,5^{\circ} \mathrm{N}, 96^{\circ} \mathrm{E}-106^{\circ} \mathrm{E}\right]$ 10-kilometer grid distance in 1990-1999 and $20-$ 2020. The reliability of the NRCM model output in ranges $0.89-0.98$ and the Agreement Index (IOA) was examined in the range of 0.76-0.95. To assess the impact of climate change on agriculture, we need fine resolutions climate data as input into the crop model. Because of the high quality of NRCM output, we here used a conservative remapping scheme for increasing grid spacing from $10 \mathrm{~km}$ to $1 \mathrm{~km}$. The key method of conservative restoration is the transition of data from one grid to another while maintaining the global and local integrations and has many very promising applications in atmospheric science. Perhaps the most immediate application would be conservative interpolation for the post-processing of numerical model data (see Lauritzen and Nair 2008 and the references therein). The equation is described in equation 1.

$$
\overline{F_{k}}=\sum_{n=1}^{N}\left[\overline{f_{n}} w_{1 n k}+\left(\frac{\partial f}{\partial \theta}\right)_{n} w_{2 n k}+\left(\frac{1}{\cos \theta} \frac{\partial f}{\partial \emptyset}\right)_{n} w_{3 n k}\right]
$$

where $\theta$ is latitude, $\phi$ is longitude, and the three remapping weights are

$$
\begin{aligned}
& w_{1 n k}=\frac{1}{A_{k}} \int_{A n k} d A, \\
& w_{2 n k}=\frac{1}{A_{k}} \int_{A n k} \theta d A-\frac{w_{1 n k}}{A_{n}} \int_{A n} \theta d A, \\
& w_{3 n k}=\frac{1}{A_{k}} \int_{A n k} \emptyset \cos \theta d A-\frac{w_{1 n k}}{A_{n}} \int_{A n} \emptyset \cos \theta d A
\end{aligned}
$$

The remapping output is compared to ground-based measures from the Department of Thai Meteorology and Highly Resolved Observational Data Integration for the 1990-99 Water Resources Assessment (APHRODITE). Statistical analyzes, such as Mean Bias, Standard Deviations, and Agreement Index were used for the evaluation of model performance.

The Mean Bias is calculated following (2).

$$
\text { Mean Bias }=\bar{M}-\bar{O}
$$

where $\bar{M}$ is Mean of Model data, $\bar{O}$ is Mean of Observation data

The standard deviation of residuals is calculated following (3).

$$
S D=\sqrt{\frac{\sum\left[\left(x_{O}-X_{M}\right)-\left(\overline{X_{O}}-\overline{X_{M}}\right)\right]^{2}}{n}}
$$

where $X_{O}$ is Observation Data, $X_{M}$ is Model Data, $\overline{X_{O}}$ is Mean of observation Data, $\overline{X_{M O}}$ is Mean of Model Data and $\mathrm{n}$ is the number of model and observation data. The index of agreement (IOA) is calculated following (4) 


$$
I O A=1.0-\frac{\sum_{i=1}^{n}(O-M)^{2}}{\left.\sum_{i=1}^{n}|M-\bar{O}|+|O-\bar{O}|\right)^{2}}
$$

where $\mathrm{O}$ is Observation data, $\mathrm{M}$ is Model data, $\bar{O}$ is Mean of Observation data, $\mathrm{n}$ is number of model and observation data

The methods described below have been reproduced in part from (https://dssat.net/about/). DSSAT is a software application program that covers crop simulation models for over 42 crops and tools for efficient application. The software application is the Decision Support System. Tools included in database management programs soil, weather, crop management, and testing data and tools, and applications programs. The crop simulation model simulates the growth, development, and output of the soil/plant/atmosphere dynamic. DSSAT and its crop simulation models have been used for a broad range of applications at different spatial and temporal scales. This includes management of the farm and precision, evaluations of regional climate variability and climate change impact, gene-based modeling and reproductive processes, water use, greenhouse gas emissions, and long-term sustainability via organic soil and nitrogen balances. The cultivars used in the study, namely KDML-105 for rice, and short-season for maize.

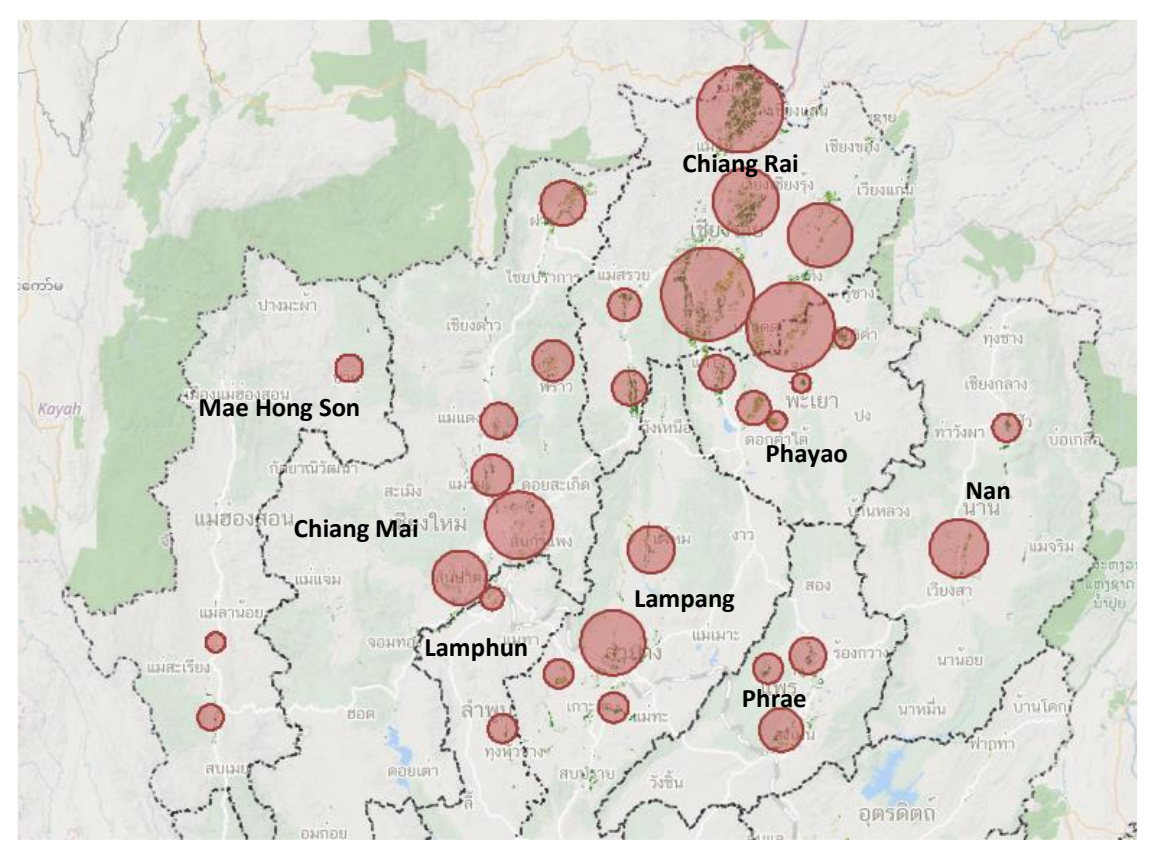

Figure 1 Planting area (red circle) in northern Thailand (gistdat.or.th)

We have performed here a Decision Support System (DSSAT) Version 4.7.5 from June to December 1990-1999 to simulate crop yield production. The output from DSSAT was compared to on-farm data from the Department of Agriculture in Thailand. The seed period is defined from June to October, while the harvest period from November to December. The seasonal growth, development, and yield of crops, together with the change in soil, water, carbon, and nitrogen balance under the cultivation system, were achieved (Jone et al., 2003). CERES-RICE, which is an individual sub-module incorporated in a DSSAT, was used for the calculation to simulate phonology, daily growth, and plant nitrogen and carbon requirements, plant materials senescence. We have selected eight provinces, including Phrae, Chiang Mai, Nan, Lamphun, Lampang, Mae Hong Son, Chiang Rai, and Phayao, based on complete 
information on overall crop production. To estimate crop production, we have used plantation areas as shown in Figure 1 for both rice and maize. Generally, maize is sown after the rice farming season. Every month, the water demand for rice was set as in Table 1 (Intaboot, 2017). The fertilizer level of $\mathrm{N}: 6 \mathrm{~kg} / \mathrm{ha}, \mathrm{P}_{2} \mathrm{O} 5: 7.5 \mathrm{~kg} / \mathrm{ha}, \mathrm{K}_{2} \mathrm{O}: 7.5 \mathrm{~kg} / \mathrm{ha}$, was used following reports from the Department of Agriculture in Thailand. The layers of soil analysis was developed at $1,035 \mathrm{~g} / \mathrm{cm}^{3}$ bulk density, $1,46 \%$ organic carbon, $0,60 \%$ of total nitrogen, $5,63 \% \mathrm{pH}, 6,5 \%$ $\mathrm{pH}$ of water, $5,766 \mathrm{mg} / \mathrm{kg}$ phosphorous, $5,766 \mathrm{~cm} / \mathrm{kg}$ potassium, and 1,46\% of the organic stable. CERES-RICE model yield simulated by the Equation as follows equation 5, (Evan, 1993; Ritchie, et al., 1998).

$$
Y=I_{H \eta R} \sum_{i=1}^{N}\left(Q_{d P A R i} R_{\eta} f_{i} \Delta_{R I}\right)
$$

$\mathrm{Y}=$ grain yield as dry matter in $\mathrm{g}^{-2} ; I_{H}=$ harvest index (grain as a fraction of the abovegroundbiomass), $\eta R$ the value of the RUE in $\mathrm{g} \mathrm{MJ}^{-2} ; Q_{d P A R i}=$ average daily total of incident PAR for a given month (i) in $\mathrm{MJm}^{-2}, f_{i}=$ fraction of PAR intercepted; ${ }_{i} R_{\eta}=$ number of days of radiation interception; $\Delta_{R I}=$ fraction of the maximum RUE depending on crop performance, in $\mathrm{gMJ}^{-2} ; \mathrm{N}$ is the number of months.

Table1. Water demand for the grown rice in each month.

\begin{tabular}{lc}
\hline Month & Water demand (mm/month) \\
\hline June & 274 \\
July & 67.8 \\
August & 49.3 \\
September & 58.5 \\
October & 32.2 \\
\hline
\end{tabular}

To predict future rice and maize production, we analyze the change in crop production by comparing future crop production (2020-2029) with the past (2010-2018) and the crop production risk. In a production risk analysis to support decisions on rice and maize farming, this decision applied three decision criteria, namely Expected Value (EV) ( Markowitz, 1989), Stochastic Dominance Analysis (SD) (Davidson et al., 2000) and Mean-Gini Dominance Analysis (MGD) ( Tsuji et al., 1998, Kisekka et al ., 2016a, Kisekka et al . , 2016b). The three criteria are commonly used in agricultural economic analysis. 


\section{Results and Discussion \\ 3.1 Model Evaluation}

Temperature, Monthly-Mean, 1990-1999

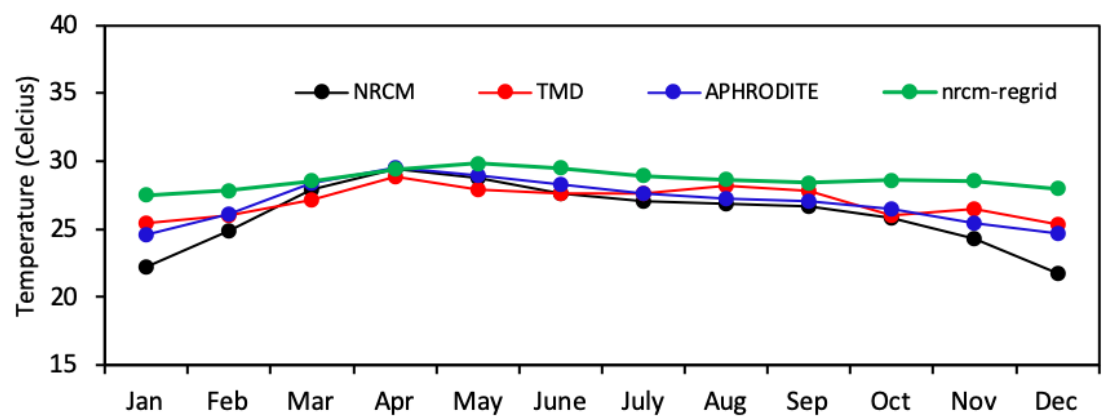

Precipitation, Monthly-Mean, 1990-1999

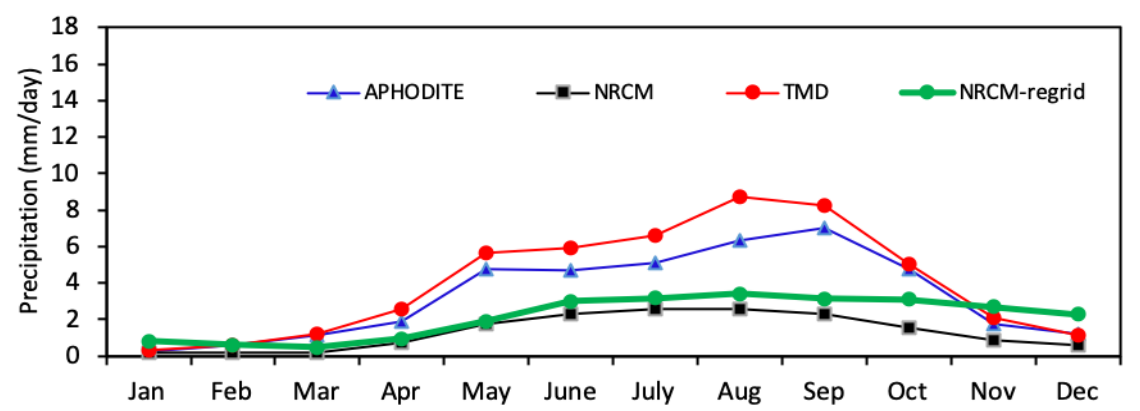

Fig.2 Monthly mean temperature $\left({ }^{\circ} \mathrm{C}\right)$ and precipitation (mm/day) averaged over 1990-1999 based on 44 station locations of Thai Meteorological Department (TMD), TMD (circle), Asian Precipitation - Highly Resolved Observational Data Integration Towards Evaluation of Water Resources (APHRODITE) (triangle), MERRA (diamond), Global Precipitation Climatology Project (GPCP) (Plus) and Nested Regional Climate Model (square).

The remapping output with $1 \mathrm{~km}$ grid spacing was compared to the original NRCM output with $10 \mathrm{~km}$ grid spacing and observation data including APHRODITE and TMD averaged over 1990-1999 44 TMD station locations are shown in Figure 2. In general, the remapping output captures well the pattern of monthly and daily temperature and precipitation. In the case of temperature, the remapping output tends to improve compared to the NRCM. By comparing the original NRCM, which was cold-biased data, the remapping output was about $0.2-2{ }^{\circ} \mathrm{C}$ warmer than the NRCM output. When the remapping output is compared to the observation, the trend is close to both TMD and APHRODIT. While the precipitation from the remapping output shows a slight difference from the NRCM. The trend is similar to the NRCM and slightly higher than the NRCM, approximately $1 \mathrm{~mm} /$ day from October to December. Remapped precipitation remains lower than bot TMD and APHRODIT. 


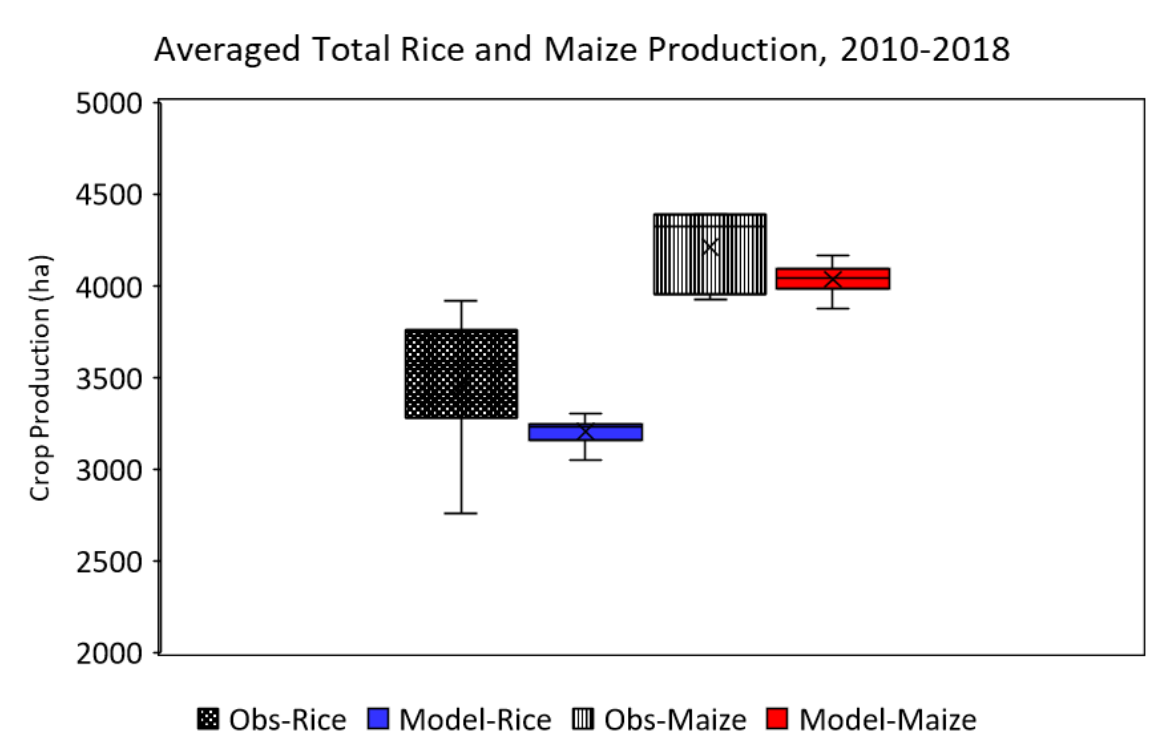

Figure 3 box plot of simulated rice and maize from DSSAT and on-farm dataset

Since no on-farm crop production data was available in 2019, simulated DSSAT rice and maize-based on CERES-Rice and CERES-Maize were compared to the on-farm dataset in 2010-2018. The assessment of both rice and maize crop production was shown in the box plot of modeled rice and maize and on-farm data in Figure 3. We found on-farm data on the thickness of wire from both rice and maize; while simulated rice and maize were thinner in the wire. The box plot analysis shows that the modeled crop production is lower than the on-farm data for both rice and maize. The actual rice production was $3200-3800 \mathrm{~kg} / \mathrm{ha}$, while the model rice was $3000-3200 \mathrm{~kg} / \mathrm{ha}$. While the modeled maize was $4000-4100 \mathrm{~kg} / \mathrm{ha}$, the real maize was $3900-4400 \mathrm{~kg} / \mathrm{ha}$.

Table 1 the statistical between the model and ground-based observations from TMD.

\begin{tabular}{ccccccc}
\hline \multirow{2}{*}{ Statistical analysis } & \multicolumn{2}{c}{ Temperature } & \multicolumn{2}{c}{ Precipitation } & \multicolumn{2}{c}{ Crop Production } \\
\cline { 2 - 7 } & NRCM & Remapping & NRCM & Remapping & Rice & Maize \\
\hline IOA & 0.76 & 0.78 & 0.63 & 0.65 & 0.89 & 0.81 \\
Mean-Biased & -0.92 & 1.62 & -2.68 & -1.88 & -245 & -176 \\
SDR & 1.87 & 1.21 & 2.54 & 2.38 & 615 & 226 \\
\hline
\end{tabular}

The statistical calculation of temperature and precipitation between model and ground-based observation data from the Thai Meteorological Department (TMD) is averaged over the period 1990-1999 from 44 TMD stations, while on-farm data for rice and maize are averaged over the period 2010-2018 from the planting area as shown in Table 1. By comparing NRCM data, the remapping output still has a high ability to capture both temperature and precipitation, which is indicated by IOA in the range from 0.65 to 0.78 . At the same time, modeled rice and maize have high IOA values of 0.81 and 0.89 . Remapped temperatures tend to be slightly overestimated with a mean bias of 1.62 , while remapped precipitation, modeled rice, and maize is underestimated compared to observations with a mean precipitation bias of $(-1.88),(-245)$ for rice and (-176) for maize. While the standard deviation of the remapping output residue ranged from 1.21 to 2.38 for the meteorological factor, crop yields ranged from 615 to 226 for rice and maize.

In summary, the model performance assessment was acceptable for both the remapping of climate output and crop production, both the re-mapping of climate output and 
crop production. The remapping output, including temperature and precipitation, remains at a high IOA value of 0.78 and 0.64 , while the temperature and precipitation change slightly compared to NRCM by 1.62 and (-1.88). As the concept of a conservative remapping method preserves the trend of the original data, the quality of the remapping data is similar to that of the NRCM data. Simulated crop production was also acceptable compared with IOA on-farm yields of 0.81 and 0.89 for rice and maize, although the model output shows an underestimation of crop production. It is likely to be based on a number of factors, such as information on irrigation and fertilization. The demand for water in this work followed Intaboot, 2017, which is a constant value for the entire simulation, but in reality, the irrigation schedule for planting was established. Irrigation is severely affected by planting efficiency. For example, it was identified as key to improving agricultural productivity (Oramah, 1996; Carruthers et al ., 1997; Huang et al., 2006) and Nonvide, 2018 reported that the percentage increase in rice yield due to irrigation was between 55\% and 60\%. However, as reported in Yousaf et al., 2017, fertilization can enhance crop production. They found that crop yields increased by 19-41 percent (rice) and 61-76 percent (rape) over the two years of NPK fertilization rotation compared to PK fertilization across the study area.

\subsection{Prediction of Rice and Maize}

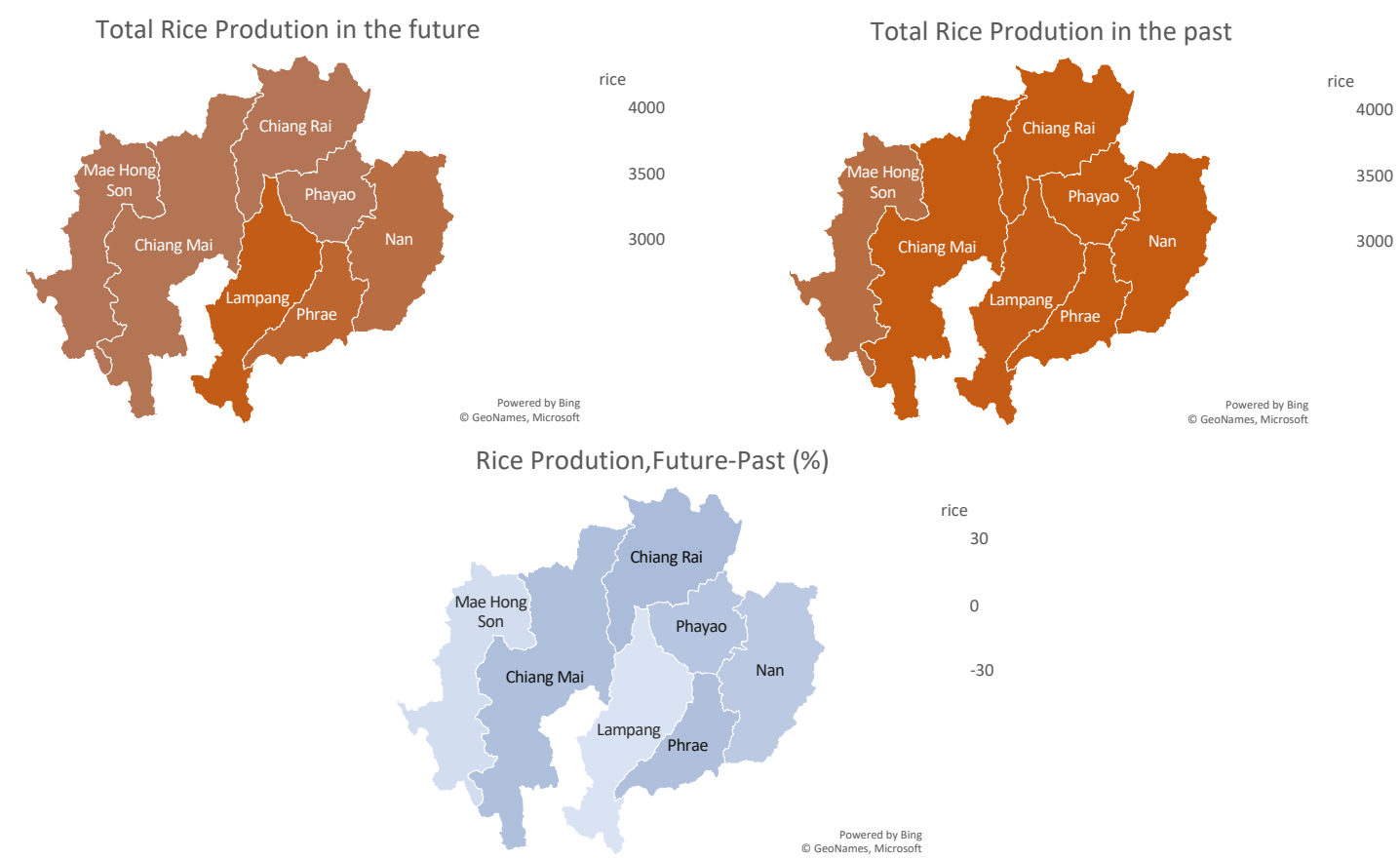

Figure 4 Averaged total rice production in wet season in the future (2020-2029), in the past (2010-2018) and difference between future change and the past. 

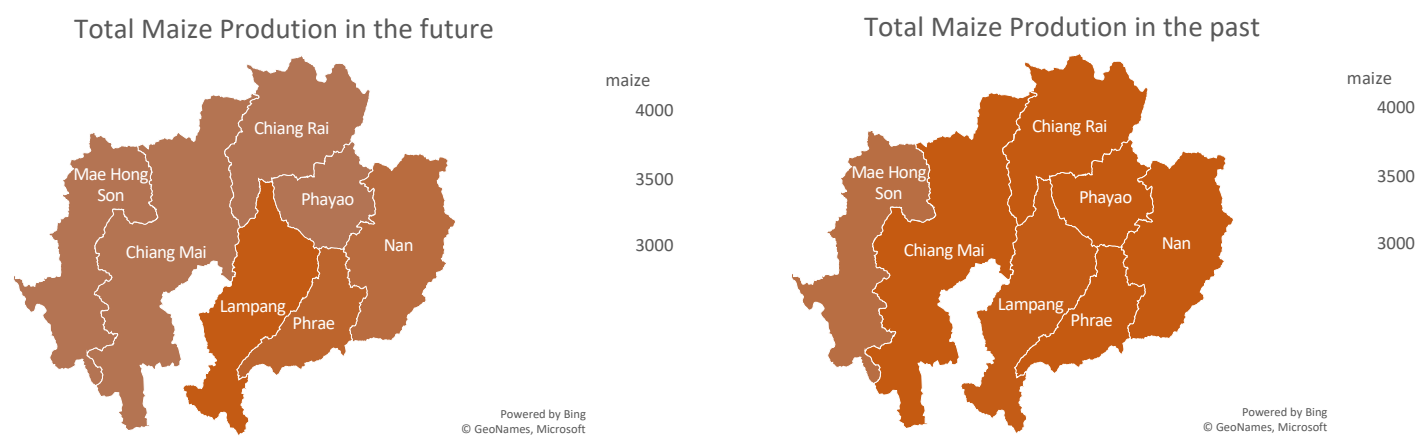

Total Maize Prodution, Future-Past (\%)

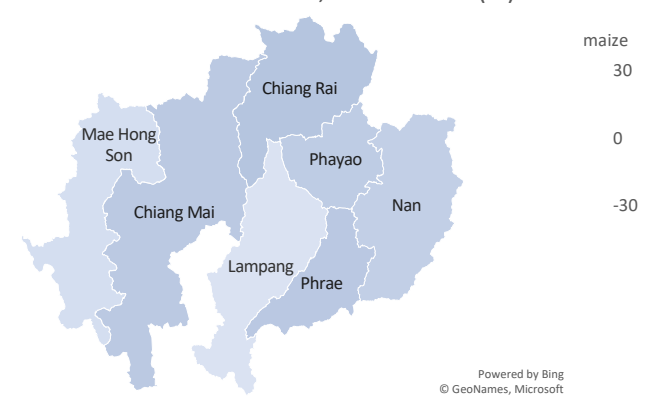

Figure 5 Averaged total maize production in the future (2020-2029), in the past (2010-2018) and difference between future change and the past.

Rice \& Maize Change in 2020-2029

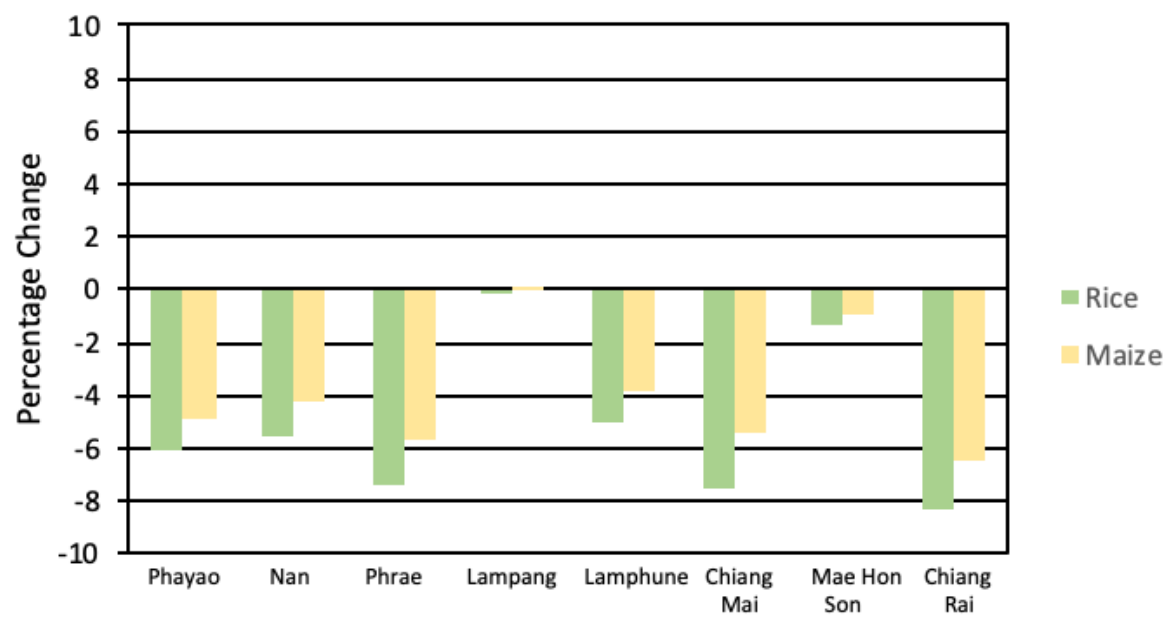

Figure 6 Percentage change of rice and maize in 2020-2029 compared to 2010-2018.

The future total production of rice and maize during 2020-2027 under the worst climate change scenario (RCP8.5) was shown in Figures 4 and 5. In general, DSSAT predicts a decrease in aggregate yields by 5.15 percent and 3.9 percent for rice and maize compared to last year's simulations. We found that Chiang Rai, Chiang Mai, and Phrae were the most declining yields in the region by about $7 \%$, while Lampang was the only province that had a slight effect on climate change of less than 1\% (Figure 6). As reported in Amnuaylojaroen and Chanvijit, 2019, future precipitation tends to decrease by approximately $0.5 \mathrm{~mm} /$ day across Thailand but increases slightly in some areas, near northern Thailand by approximately $0.5 \mathrm{~mm}$ / day. In contrast, $2 \mathrm{~m}$-temperature tends to rise about $2-5^{\circ} \mathrm{C}$ in Thailand. The combined effect of climate change between increased temperatures and reduced rainfall would have an 
impact on agricultural irrigation. The result is very statistically significant. Lower aggregate yields under climate change conditions compared to previous years may be due to lack of water for agriculture, especially rice that is irrigated is positively associated with improved rice productivity (Nonvide, 2018). While temperature increases tend to be sensitive to maize production.

\subsection{Crop Production Risk Analysis}

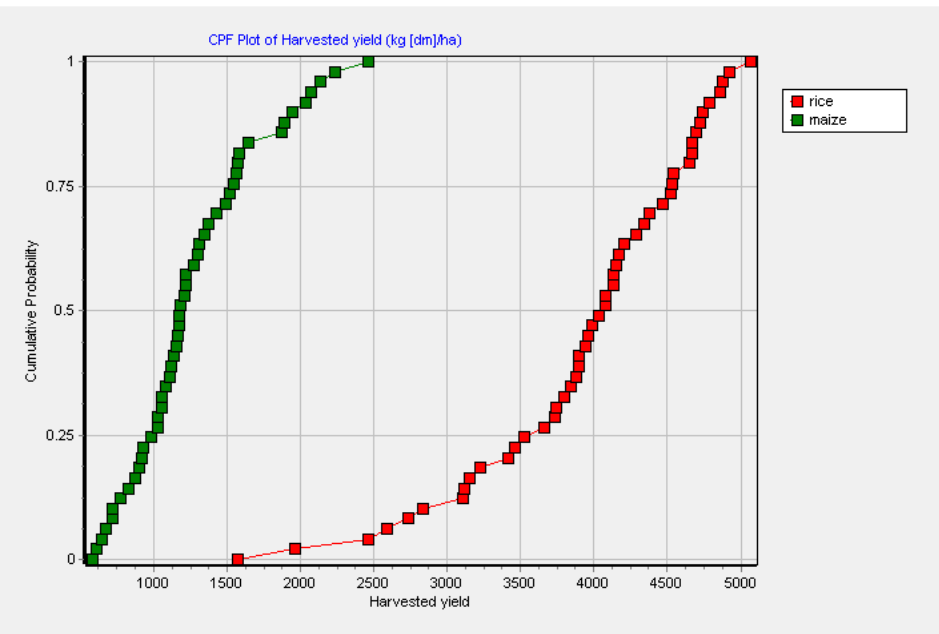

Figure 7 Cumulative probability distribution of rice and maize production in the future

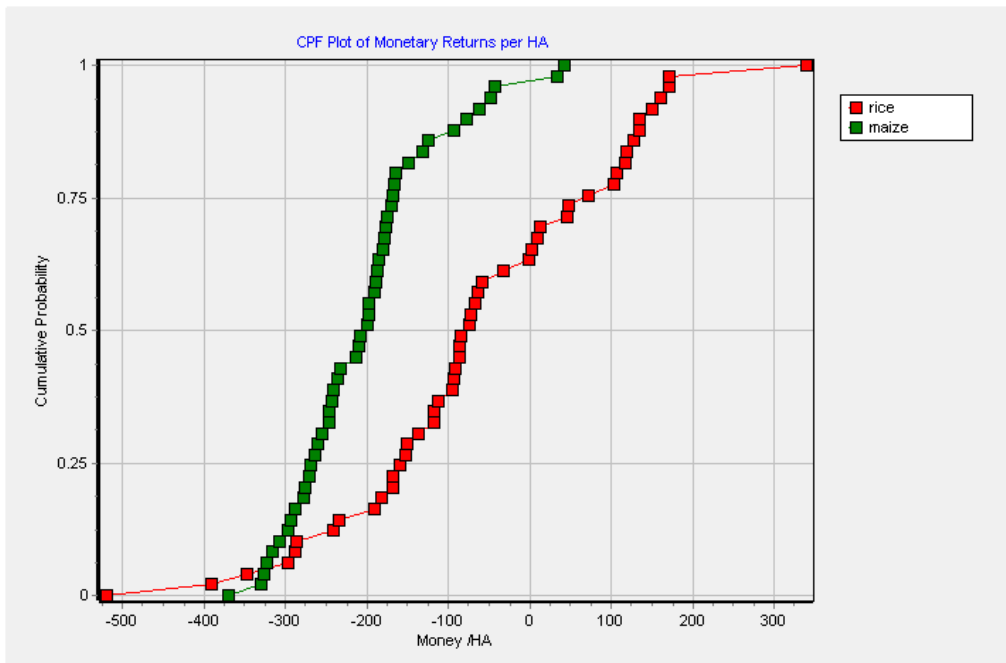

Figure 8 Stochastic dominance analysis $(\$ / \mathrm{ha})$ of rice and maize production in the future

The cumulative probability distribution (CPD) plots at 0,5 show that both rice and maize have been predicted to have the highest mean yield (Figure 7). Even with the predicted mean yield variance, which was smaller for maize and maximum for rice, this pattern was consistent and suggested that maize could be considered as risky among non-risk farmers. With about the $3000 \mathrm{~kg}$ of ha-1 and $4312 \mathrm{~kg}$ of ha-1 estimated regarding rice and maize yields to satisfy of the average in northern Thailand (Office of Agricultural Economics, 2020) the maize showed the cumulative probability of yield below the minimum acceptable threshold of $50 \%$, while rice shows an acceptable probability above the minimum of $30 \%$. This suggests that maize is highly likely to yield below the lowest acceptable yield target. Similarly, stochastic dominance analysis showed that both rice systems were less hazardous than maize, because they lied on the right side of rice, with the two rice systems with the lowest monetary return 
variations (Figure 8). The Mean-Gini Dominance (MDG) test showed riced as the most efficient system of management (Table 2).

Table 2 Dominance analysis of rice and maize in the near future

\begin{tabular}{cccc}
\hline Treatment & $\mathrm{E}(\mathrm{x})$ & $\mathrm{E}(\mathrm{x})-\mathrm{F}(\mathrm{x})$ & Efficient (yes/no) \\
\hline Rice & -63 & -157.4 & Yes \\
Maize & -203.7 & -253.6 & No \\
\hline
\end{tabular}

Coping with the impact of climate change on agriculture, in particular on agricultural production mainly rice and maize. Thailand's Government has initiated research on a global climate mitigation action plan and offers information to raise understanding of climate change, and many rice farmers have inadequate expertise to effectively maintain their farms in the light of changing climate conditions. Farmers have historically grown domestic rice through seeds and seedlings that are resistant primarily to pre-cultivation pests and diseases. The Thai Government sponsored new GM (deep-water) rice (not reusable) species in the program, which are typically more than one month in floodwaters of more than $50 \mathrm{~cm}$. Usage of DNA technology, and distribution of new dried-resistant rice varieties to the areas affected by dryness - gluten-resistant RD12 and non-glutinous RD33. Nevertheless, as the government does not supply sufficiently to all farmers, this new variety is also produced by various private companies. Consequently, farmers who can purchase them showed interest in new rice varieties that yield more than conventional rice. The most common improvement strategies used for those who cannot provide new seeds consisted of adjusting crop patterns, and crop schedules and improving farm management. The government has also developed land to protect rice farms from flood damage. Furthermore, risk management systems should be incorporated into national adaptation strategies for households. This may involve crop insurance or more flexible livelihoods such as integrated aquaculture and farming systems, allowing farmers to rely on land adequacy and water availability changes. In the short term, integrated agriculture increases various crop yield types while increasing the sustainability of agricultural systems is a longterm gain.

\section{Conclusion}

The purpose of this research is to forecast the future production of rice and maize in northern Thailand (2020-2029). Climate datasets from the Nested Regional Climate Model (NRCM) simulation, with an 80-90 percent reliability 10-kilometer spatial resolve (Amnuaylojaroen et al. 2019) is reduced to $1 \mathrm{~km}$ by using the Conservative First and SecondOrder Remapping schemes. This data set was then used as an environmental data collection in the DSSAT modeling framework for evaluating rice and maize production and in the risk assessment for development to support decision-making in the near future in the Decision Support System for the Transfer of Agrotechnology. The model evaluation of climate and agricultural data kept climate data at the same reliability level as the previous dataset. The data accuracy was calculated at 0.78 for the temperature and 0.65 for the precipitation according to the Agreement Index (IOA), while the average Biased was 1.62 for the temperature and (-1.88) for the precipitation. Simultaneously, the results of the DSSAT model system, including the production of rice and maize, were found to be close to the on-farm data set with IOA values of 0.89 and 0.81 for rice and maize. The climate in 2020-2019 was a favorable situation, as addressed in Amnuaylojaroen and Chanvijit in 2019, with a lack of water with agriculture, with rising temperatures and decreases in precipitation. Both considerations are consistent with the findings of rice and maize yield simulations. More temperature-sensitive maize production in 
the upper Northern Region appears to decrease by more than $4 \%$. Although rice is more prone to precipitation, it also decreases by about $6 \%$ for the entire region. Nonetheless, the risk analysis of rice and maize production in the near future has shown that maize cultivation is likely in the near term to face a high risk of low production as a result of climate change, while there can be a low risk of rice cultivation.

\section{Acknowledgment}

The study was supported by Biodiversity-Based Economy Development Office (BEDO) under National Research Council of Thailand (NRCT) project. We are thankful for the Thai Meteorological Department (TMD) providing their and meteorological (temperature and precipitation) observation data and Department of Agriculture for rice and maize production data.

\section{Reference}

1. Adnan, A. A., et al. 2017. CERES-Maize model for determining the optimum planting dates of early maturing maize varieties in Northern Nigeria. Frontiers in plant science 8: 1118.

2. Amnuaylojaroen, T. and Chanvichit, P. 2019. Projection of near-future climate change and agricultural drought in Mainland Southeast Asia under RCP8. 5. Climatic Change 155(2), 175-193.

3. Arritt, R. W. and Rummukainen, M. 2011. Challenges in regional-scale climate modeling. Bulletin of the American Meteorological Society. 92(3), 365-368.

4. Attavanich, W. 2013. The effect of climate change on Thailand's agriculture. 7th International Academic Conference Proceedings. Accessed 2 August 2020.

5. Berry, S. T. et al., 2014. Corn production shocks in 2012 and beyond: Implications for harvest volatility. The Economics of Food Price Volatility, University of Chicago Press, 59-81.

6. Caldwell, P. et al., 2009. Evaluation of a WRF dynamical downscaling simulation over California. Climatic Change, 95(3-4), 499-521.

7. Carruthers, I., et al. 1997. Irrigation and food security in the 21 st century." Irrigation and Drainage Systems, 11(2), 83-101.

8. Cayan, D. R., et al. 2008. Climate change scenarios for the California region." Climatic Change 87(1), 21-42.

9. Chen, F. and Dudhia, J. 2001. Coupling an advanced land surface-hydrology model with the Penn State-NCAR MM5 modeling system. Part I: Model implementation and sensitivity. Monthly Weather Review, 129(4), 569-585. 
10. Davidson, R. and Duclos, J. Y. 2000. Statistical inference for stochastic dominance and for the measurement of poverty and inequality. Econometrica 68(6), 1435-1464.

11. Duffy, P., et al. 2006. Simulations of present and future climates in the western United States with four nested regional climate models. Journal of climate, 19(6), 873-895.

12. Evans, J. R. (1993). Photosynthetic acclimation and nitrogen partitioning within a lucerne canopy. II. Stability through time and comparison with a theoretical optimum. Functional Plant Biology, 20(1), 69-82.

13. Gent, P. R., et al. 2011. The community climate system model version 4. Journal of climate, 24(19), 4973-4991.

14. Giorgi, F., et al. 2001. Regional climate information — evaluation and projections."

15. Giorgi, F., et al. 2009. Addressing climate information needs at the regional level: the CORDEX framework. World Meteorological Organization (WMO) Bulletin 58(3), 175.

16. Giorgi, F. and Mearns, L. O. 1991. Approaches to the simulation of regional climate change: a review. Reviews of Geophysics, 29(2), 191-216.

17. Hayhoe, K., et al. 2004. Emissions pathways, climate change, and impacts on California. Proceedings of the national academy of sciences 101(34), 12422-12427.

18. Huang, Q., et al. 2006. Irrigation, agricultural performance and poverty reduction in China.Food policy, 31(1), 30-52.

19. Iacono, M. J., et al. (2008). Radiative forcing by long-lived greenhouse gases: Calculations with the AER radiative transfer models. Journal of Geophysical Research: Atmospheres, 113(D13).

20. Intaboot, N (2017) The study of water demand to grow rice in Thailand. 6th International Symposium on the Fusion of Science and Technologies (ISFT2017) Jeju, S. Korea 17th $\quad-\quad 21$ st July. http://www.rdi.rmutsb.ac.th/2011/digipro/isft2017/CA/11.\%5BCA003\%5D_F.pdf. Accessed 2 August 2020.

21. Jones, J. W., et al. (2003). "The DSSAT cropping system model." European journal of agronomy, 18(3-4), 235-265. 
22. Kerr, R. A. 2011. Vital details of global warming are eluding forecasters, American Association for the Advancement of Science.

23. Kharin, V. V. and Zwiers, F. W. 2002. Climate predictions with multimodel ensembles. Journal of climate, 15(7), 793-799.

24. Kisekka, I., et al. 2016. Assessing deficit irrigation strategies for corn using simulation. Transactions of the ASABE, 59(1), 303-317.

25. Kisekka, I., et al. 2016. Mobile drip irrigation evaluation in corn." Kansas Agricultural Experiment Station Research Reports, 2(7), 8.

26. Markowitz, H.M. 1989. Mean—Variance Analysis. In: Eatwell J, Milgate M, Newman P (ed) Finance. The New Palgrave. Palgrave Macmillan, London.

27. Meehl, G. A., et al. 2007. The WCRP CMIP3 multimodel dataset: A new era in climate change research. Bulletin of the American Meteorological Society, 88(9), 1383-1394.

28. Nonvide, G. M. A. 2018. A re-examination of the impact of irrigation on rice production in Benin: An application of the endogenous switching model. Kasetsart Journal of Social Sciences.

29. Oramah, B. 1996. The direct private benefits of participation in a publicly provided surface irrigation scheme in the high rainfall area of Nigeria. African Development Review 8(1), 146-172.

30. Pierce, D. W., et al. (2013). Probabilistic estimates of future changes in California temperature and precipitation using statistical and dynamical downscaling. Climate Dynamics, 40(3-4), 839-856.

31. Ritchie, J. 1986. IBSNAT/CERES rice model" Agrotechnology Transfer, 3, 1-5.

32. Ritchie, J., et al. 1998. Cereal growth, development and yield. Understanding options for agricultural production, Springer, 79-98.

33. Salathé, E. P., et al. 2010. Regional climate model projections for the State of Washington. Climatic Change, 102(1-2), 51-75.

34. Salathe Jr, E. P., et al. 2008. A high-resolution climate model for the US Pacific Northwest: Mesoscale feedbacks and local responses to climate change. Journal of climate, 21(21), 5708-5726.

35. Schmidt, G. 2010. THE REAL HOLES IN CLIMATE SCIENCE. Nature 463: 21. 
36. Skamarock, W. C., et al. 2008. A description of the Advanced Research WRF version 3. NCAR Tech. Note NCAR/TN-475+ STR, Citeseer.

37. Stauffer, D. R. and Seaman, N. L. 1990. "Use of four-dimensional data assimilation in a limited-area mesoscale model. Part I: Experiments with synoptic-scale data." Monthly Weather Review 118(6), 1250-1277.

38. Taylor, K. E., et al. 2012. An overview of CMIP5 and the experiment design. Bulletin of the American Meteorological Society, 93(4), 485-498.

39. Tebaldi, C., et al. 2005. Quantifying uncertainty in projections of regional climate change: A Bayesian approach to the analysis of multimodel ensembles. Journal of climate, 18(10), 1524-1540.

40. Thompson, G., et al. 2004. Explicit forecasts of winter precipitation using an improved bulk microphysics scheme. Part I: Description and sensitivity analysis. Monthly Weather Review, 132(2), 519-542.

41. Tsuji, G. Y., et al. 1998. Understanding options for agricultural production, Springer Science \& Business Media.

42. Wilby, R. L. and Wigley, T. M. 1997. Downscaling general circulation model output: a review of methods and limitations. Progress in physical geography, 21(4), 530-548.

43. Yasutomi, N., et al. (2011). Development of a long-term daily gridded temperature dataset and its application to rain/snow discrimination of daily precipitation. Global Environmental Research, 15(2), 165-172.

44. Yousaf, M., et al. 2017. Effects of fertilization on crop production and nutrientsupplying capacity under rice-oilseed rape rotation system. Scientific reports, 7(1), 1-9 